\title{
Desenho infantil: variações sobre o mesmo tema
}

Children's drawing: variations on the same theme

\author{
Laís C. Licheski
}

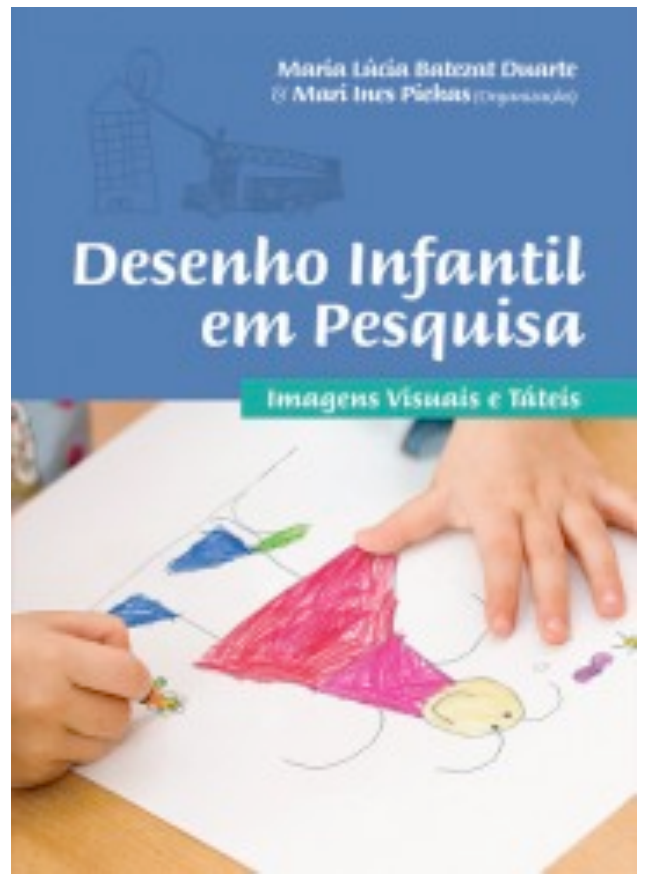

DUARTE, M. L. B. (Org.) ; PIEKAS, M.I. (Org.).

Desenho infantil em pesquisa: imagens visuais e táteis. 1.ed. Curitiba, PR: Insight, 2011. v.1. 184p.

\section{Resumo da obra}

Desenho infantil em pesquisa reúne seis projetos individuais de pesquisa, sínteses de dissertações de mestrado, que abordam o papel do desenho na infância e no desenvolvimento humano, e um artigo que indica os fundamentos teóricos, métodos e instrumentos de pesquisa partilhados pelas autoras. A obra apresenta indagações e possíveis caminhos para respondê-las a partir de investigação teórica e de estudos de caso.

\section{Summary of the book}

Desenho infantil em pesquisa brings together six individual research projects which address the role of drawing in childhood and human development. Also presents an article that indicates the theoretical foundations, methods and research tools shared by the authors. The work introduces questions and possible ways to answer them from theoretical research and case studies

\section{Introdução}

Sínteses de dissertações de mestrado apresentadas ao Programa de Pós-Graduação em Artes Visuais da Universidade do Estado de Santa Catarina - UDESC, produzidos sob orientação da profa $^{a}$ Maria Lúcia Batezat Duarte, cada capítulo desse livro oferece ao leitor a oportunidade de conhecer um projeto de pesquisa individual a partir de uma abordagem teórica em comum, na qual se destacam como referências os nomes de Bernard Darras, Georges-Henri Luquet, Brent Wilson e Lev Vygotsky . 
A obra se estrutura em um crescendo, apresentando desde a mãe/pesquisadora documentando os desenhos dos primeiros anos de seus filhos, passando pela professora observando alunos em fase de alfabetização, pela coleta de desenhos de crianças de ambientes escolares e culturais distintos, até as representações gráficas de crianças e adolescentes surdos e cegos.

\section{As variações}

O tema desenho infantil é abordado a partir de perguntas de pesquisa que the conferem alguma variação. Ao destacar algumas dessas perguntas, é possível perceber pontos interessantes explorados ou ainda a explorar. Observar esses questionamentos pode auxiliar o leitor a construir um quadro geral dos estudos apresentados.

\section{Por que a criança desenha?}

Com essa pergunta de Alessandra Klug, destaca-se no primeiro capítulo a concepção do desenho infantil com finalidade comunicacional, como forma de comunicação entre os sujeitos na cultura (Darras, 1996). De acordo com Luria (1990), em crianças os processos de pensamento são, por natureza, gráficos e baseados na memória. Nessa perspectiva, o desenhar não é visto apenas como atividade lúdica, um passatempo infantil, mas como um ato de socialização e educação, a representação gráfica, enquanto linguagem, tão importante quanto a fala ou a escrita e completamente integrada às atividades da criança.

\section{Qual a contribuição do desenho infantil na alfabetização?}

No capítulo dois é possível perceber a importância do desenho infantil para a apreensão e compreensão do mundo, para a construção de categorias semânticas e das generalizações e processos de abstração que são necessários para o desenvolvimento da fala e da escrita. Percebe-se no texto de Marice Kincheski Fassina uma tendência à abordagem da linguagem baseada na experiência e na maneira que o indivíduo percebe e conceitualiza o mundo, e sua dependência do contexto e dos modelos culturais, como comentado por Ungerer \& Schimid (1996).

\section{Como o desenho infantil se estabelece em ambientes com informações visuais diferentes?}

González Ochoa (1986) comenta que o "ver" é convencional, cultural, construído, e os modos de ver são resultado social; assim, a capacidade de entender uma linha ou um esboço é uma habilidade adquirida, convencional, que requer aprendizagem, e a compreensão do visual se baseia em convenções histórica e socialmente variáveis.

No capítulo três, por Camilla Carpanezzi La Pastina, destaca-se a noção da aprendizagem social do desenho e da reprodução de formas e estilos por meio da transmissão de desenho entre gerações, o que faz lembrar Luria (1990) ao comentar como a experiência compartilhada por uma sociedade é transmitida através de seu sistema linguístico.

\section{Como se compõe o repertório gráfico de uma criança surda com relação ao de uma criança ouvinte?}

Em sua análise do desenho infantil em um contexto de surdez, Liane Carvalho Oleques investiga a produção gráfica de uma criança surda e uma ouvinte, apontando as características formais e figurativas das entidades representadas e analisando-as. Nas análises destacam-se os conceitos de generalização versus especificidade, nível de base e nível subordenado, tornando possível uma aproximação ao universo da aquisição de repertório visual condicionada ao conhecimento do mundo, mediado ou não pela linguagem oral.

\section{Uma criança cega poderia realizar os mesmo desenhos do vocabulário gráfico das crianças standards? E o resultado seria semelhante?}

Protótipos (pontos de referência cognitivos) bem definidos são fundamentais para a formulação das categorias cognitivas. (Ungerer \& Schmid, 1996). Para identificação de elementos desconhecidos, os protótipos são ponto de partida na ocorrência de processos mentais de categorização que concorrem para a aquisição de linguagens. Mari Ines Piekas destaca, no capítulo cinco, o ensino de desenho para crianças cegas como forma de Ihes facilitar a aquisição 
de protótipos bidimensionais por percepção tátil, aumentando seu repertório e sua possibilidade de comunicação.

\section{Crianças e adolescentes cegos identificam e compreendem ilustrações em relevo em livros táteis?}

Ao apresentar os resultados de sua pesquisa de campo com livros inclusivos e ilustração tátil, Márcia Cardeal, autora do sexto capítulo, conclui que a função háptica não é integradora como a visão, mas é fragmentada e lenta. Audição e tato relacionam-se ao tempo; a visão, ao espaço. A imposição de códigos visuais, nesse caso, é ineficaz, já que as transcrições em relevo de imagens são concebidas em sua origem para a percepção visual.

\section{Afinal, como e por que a criança desenha? 0 que dizer e pensar sobre 0 ato de desenhar?}

O texto de Maria Lúcia Batezat Duarte procura esclarecer as opções por fundamentos teóricos, métodos e instrumentos de pesquisa ao se trabalhar com desenho de crianças e adolescentes.

Destaca-se a escolha pela fundamentação na semiótica cognitiva dialógica. As pesquisas em semiótica, atualmente, se encontram com as das ciência cognitivas, de acordo com o Centre de Recherche Images, Culture et Cognition de L'Université Paris (http://imagesanalyses.univparis1.fr). Assim, a abordagem pragmática é complementada por uma abordagem das modalidades de construção do conhecimento à partir do ambiente, notadamente pelas mediações sensório-motoras, sociais, semióticas, tecnológicas e midiáticas.

A semiótica cognitiva adota uma atitude dialógica concebida para explorar o papel das imagens nas relações entre o indivíduo e seu o ambiente, por um lado, e as funções das imagens no conhecimento e comunicação, por outro lado, assegurando a ligação entre as ciências cognitivas e as neurociências e as abordagens contextualistas, construtivistas e pragmáticas de pesquisa (Darras, 2003, tradução livre da autora).

A opção pela pesquisa qualitativa e pelo estudo de caso como modo de investigação faz sentido dentro dessa opção de fundamentação teórica. Mesmo que as autoras procurem manter um certo distanciamento acadêmico, essas opções conferem às pesquisas um ar intimista, mas que permitem análises transversais capazes de revelar um grande número de informações sobre o público pesquisado e sua produção imagética, e estabelecer relações entre ao ambiente social e cultural e a aquisição de linguagens e conhecimentos pela análise dessa produção.

\section{Considerações}

Ainda que de maneira geral os métodos e técnicas sejam apresentados de forma clara e concisa, a difícil tarefa de transmitir em poucas páginas a complexidade de uma pesquisa pode gerar dúvidas para o leitor: o que é obvio para o pesquisador não é claro o suficiente para preencher as lacunas deixadas pela omissão de explicações.

É recomendável a revisão geral do texto. A errata anexada ao volume corrige informações que comprometem a interpretação de figuras e alguns problemas menores, mas ainda assim verificase a existência de algumas imprecisões gramaticais e de pontuação, bem como a omissão ou falta de clareza de informações, principalmente as que se referem às imagens que acompanham os textos. No primeiro artigo, por exemplo, o diagrama apresentado carece de um formulação gráfica mais elucidante. As ligações sugeridas pelas linhas que unem os quadros não esclarecem a troca e reciprocidade entre os elementos do esquema de conjunto proposto, e sua compreensão e correta interpretação não são autônomas, mas dependem do texto subsequente.

A apreciável intenção da sequência dos capítulos, que conduz o leitor do ambiente familiar ao escolar e ao social mais complexo, pode ser subvertida para melhor apreciação do conteúdo. Apesar da apresentação de Duarte contribuir para o entendimento geral da obra, é o capítulo final, por ela escrito, que elucida a escolha das referências teóricas e muitas das dúvidas geradas pela leitura dos demais artigos.

As variações sobre o tema desenho infantil ocorrem em relação às especificidades dos objetos de estudo. Não se percebe variação no que diz respeito à escolha de autores e métodos. Chama a atenção a opção pela mesma gama de autores de base, especialmente Darras, numa continuidade dos estudos anteriores de Duarte. 
A obra como um conjunto, aliás, é marcada pela influência de Duarte e reflete as pesquisa conduzidas pelos integrantes do GIADE (Grupo de Pesquisa Imagem, Arte e Desenho na Escola, UDESC/CNPq), que procura demonstrar e valorizar o desenho infantil e adolescente, apresentando-o como fator identitário, comunicacional e cognitivo. Há que se considerar que as habilidades visuais e de percepção espacial e os conhecimentos a elas associados são pouco explorados na formação escolar, se comparados à massiva quantidade de mensagens visuais consumida atualmente por meio das mídias ao alcance de crianças e adolescents..

A iniciativa dessa publicação tem o mérito de, talvez, incentivar a leitura das pesquisas completas e servir como referencial para a realização de novos estudos. E tem o potencial de estimular o diálogo entre autores de outras linhas de pesquisa, ampliando os fundamentos teóricos e os resultados, com sua finalidade educacional expandida para atividades concretas de amplo alcance.

\section{Referências}

CENTRE DE RECHERCHE IMAGES, CULTURE ET COGNITION DE L'UNIVERSITÉ PARIS. In: http://imagesanalyses.univ-paris1.fr. Acesso em nov. 2012.

DARRAS, B. 1996. Au commencement était l'image: du dessin de l'enfant à la communication de I'adulte. Paris: ESF Éditeur.

DARRAS, B. 2003. La modelisation semiocognitive à l'epreuve des resultats des neuroscience: le cas de la production des schémes graphiques. Recherches en communication, n. 19. p. 175197

GONZÁLEZ OCHOA, C. 1986. Imagen y sentido: elementos para una semiótica de los mensajes visuales. México: Universidad Nacional Autónoma de México.

LURIA, A. 1990. Desenvolvimento cognitivo: seus fundamentos culturais e sociais. São Paulo:Ícone.

UNGERER, F. \& SCHIMID, H. 1996. An introduction to cognitive linguistics. London: Longman.

VYGOTSKY, L. 2001. A construção do pensamento e da linguagem. São Paulo: Martins Fontes.

\section{Sobre a autora}

Laís Cristina Licheski, graduada em Comunicação Visual (UFPR, 1988), especialista em História da Arte (PUC-PR, 1993), mestre em Educação (PUC-PR, 1998), doutora em Ergonomia (UFSC, 2004), é professora dos cursos de graduação e especialização do Departamento Acadêmico de Desenho Industrial da UTFPr desde 1988. Desenvolve estudos em ergonomia, design gráfico, design de informação, semiótica e ilustração nos grupos de pesquisa "Ergonomia" e "Design" da UTFPR.

<laislic@utfpr.edu.br>

[Artigo recebido em dezembro de 2012, aprovado em dezembro de 2012] 